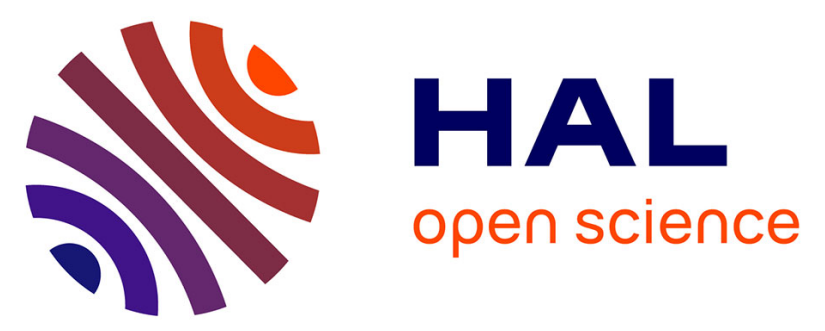

\title{
Performance of HKUST-1 Metal-Organic Framework for a VOCs mixture adsorption at realistic concentrations ranging from 0.5 to 2.5 ppmv under different humidity conditions
}

\author{
V. Chevalier, J. Martin, D. Peralta, A. Roussey, F. Tardif
}

\section{To cite this version:}

V. Chevalier, J. Martin, D. Peralta, A. Roussey, F. Tardif. Performance of HKUST-1 Metal-Organic Framework for a VOCs mixture adsorption at realistic concentrations ranging from 0.5 to 2.5 ppmv under different humidity conditions. Journal of Environmental Chemical Engineering, 2019, 7, pp.103131 -. 10.1016/j.jece.2019.103131 . hal-03487025

\section{HAL Id: hal-03487025 \\ https://hal.science/hal-03487025}

Submitted on 20 Dec 2021

HAL is a multi-disciplinary open access archive for the deposit and dissemination of scientific research documents, whether they are published or not. The documents may come from teaching and research institutions in France or abroad, or from public or private research centers.
L'archive ouverte pluridisciplinaire HAL, est destinée au dépôt et à la diffusion de documents scientifiques de niveau recherche, publiés ou non, émanant des établissements d'enseignement et de recherche français ou étrangers, des laboratoires publics ou privés.

\section{(ㄷ)(1) $\$$}

Distributed under a Creative Commons Attribution - NonCommerciall 4.0 International 
Version of Record: https://www.sciencedirect.com/science/article/pii/S2213343719302544

Manuscript_f88c2a8cdce51af3085e59c3aa0e0126

Title: Performance of HKUST-1Metal-Organic Framework for a VOCs mixture adsorption at realistic concentrations ranging from 0.5 to $2.5 \mathrm{ppmv}$ under different humidity conditions

Authors:V. Chevalier ${ }^{a, b}, *$, J. Martin ${ }^{a}$, D. Peralta ${ }^{b}$, A. Roussey ${ }^{b}$, F. Tardif ${ }^{b}$

\title{
Affiliations:
}

${ }^{a}$ SAFRAN Filtration Systems, 87800 Nexon, France

bUniv. Grenoble Alpes, CEA-Liten, 38000 Grenoble, France

Contact email:chevalier.vincent1@gmail.com

\begin{abstract}
In this study, HKUST-1 framework utilization as an adsorbent was characterized in realistic indoor air conditions. Adsorption capacities and breakthrough behaviors of this material were studied for low concentration gas mixtures with controlled relative humidity. Results demonstrate high adsorption capacities $(23.8,14.7,16.5,5.0$, and $1.4 \%$ wt for the respective mono-pollutant gases: toluene, o-xylene, ethanol, acetone and acetaldehyde). The adsorption capacities and breakthrough curves of binary and five gases mixtures give information about the competitions between pollutants and show that the studied volatile organic compounds (VOCs) are adsorbed in the order of: o-Xylene>Acetone>Toluene. Cold desorption tests were also conducted and showed a $50 \%$ decrease of the adsorption capacity after three cycles.
\end{abstract}

Keywords: VOCs adsorption, Realistic concentration, HKUST-1, Breakthrough curve, Mixture of pollutant, Humidity

\section{Introduction}

Volatile Organic Compounds (VOCs) in indoor environments represent today a major concern in terms of public health. Aromatic, alcohol and carbonyl compounds are very often present in indoor air [1-3]. Todate, several new mitigation methods such as biological degradation $[4,5]$, catalytic oxidation [6,7]and condensation have 
been investigated, but finally the adsorption process through the use of e.g. activated carbon, zeolite, mesoporous silica is still the most used and even continues to progress in terms of research efforts [8-10]. However, due to experimental metrology issues, there is a dearth of literature discussing the adsorption of VOCs mixtures at realistic low concentrations encountered in indoor environments. This issue prompted us to develop a homemade flow adsorption equipment dedicated to this kind of experiment.

Since a decade, Metal-Organic Frameworks (MOFs) materials are especially investigated, because of their high adsorption capacity and selectivity for VOCs. Their high surface areas, large porous volumes and many available metal sites that can interact strongly with gaseous molecules make them adsorbents of great interest [11-13]. MOFs are composed of metals clusters connected by organic ligands. The huge choice of combinations between binders and metals allows synthetizing more than 10000 different structures [14].The HKUST-1 framework (material formula: $\mathrm{Cu}_{3}\left(\mathrm{C}_{9} \mathrm{H}_{6} \mathrm{O}_{6}\right)_{2}$ ), composed of a copper "paddle wheel" (Figure 1), presents one of the highest densities of metal sites and some studies have shown that it is efficient to adsorb VOCs $[11,15,16]$. Another strong point of this material is its multi-cages porous network. Two large cages with an opening diameter of $9 \AA$ and internal diameters of 13.2 and $11.1 \AA$ are connected to tetrahedral shaped small cages (named "side pockets") of $6 \AA$ with a triangular shaped window of $4.5 \AA$ (Figure 2).The opening diameter of pores could be smaller in the hydrated form (Figure 2 (a)); i.e. with side pockets windows around $3.5 \AA$ [17]. 


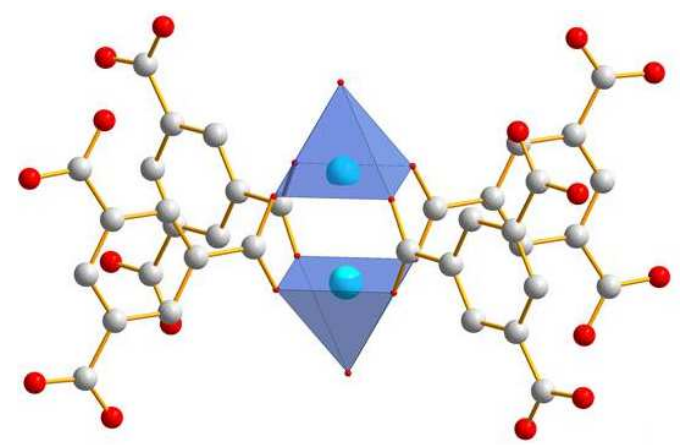

Figure 1: Copper paddle-wheel structure is composed of copper dimers and BTC anions. Copper is represented in blue, oxygen in red and carbon in grey.
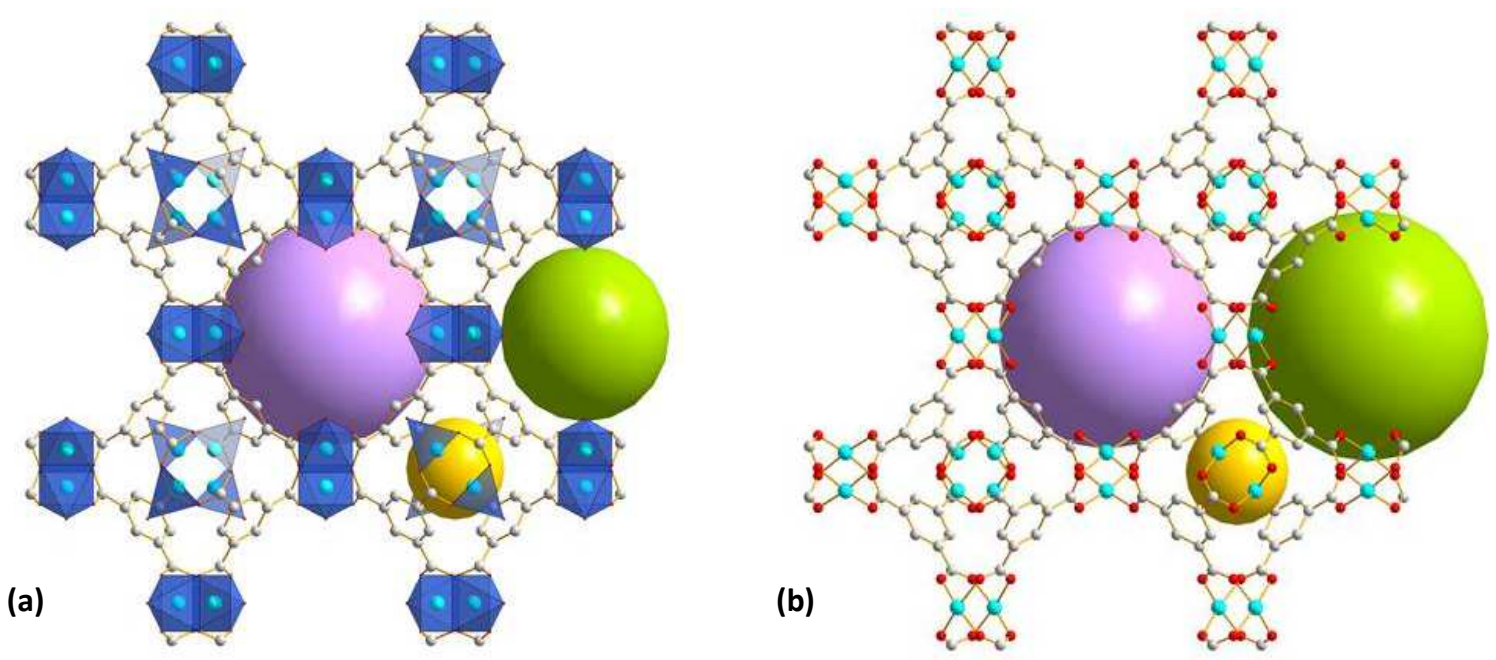

Figure 2: Representation of (a) hydrated and (b) activated HKUST-1 structures. The oxygen atoms from adsorbed water molecules are at the top of the blue pyramids. Three types of pores: the two biggest pores are in purple and green, and the smallest pore (side pocket) in yellow.

The literature includes few experimental data at very low concentrations for a mixture of pollutants, especially concerning MOFs [15]. Indeed, the adsorption studies on the MOFs are generally realized for mono-pollutants at concentrations ranging from 100 to 1000 ppmv [18-20]. In this work, a HKUST-1 adsorbent was synthesized and its adsorption performances were measured in dynamic mode for mono-pollutant and multi-pollutant mixtures at concentrations ranging from 0.5 to $2.5 \mathrm{ppmv}$ for each pollutant. Toluene, o-xylene, ethanol, acetone and 
acetaldehyde have been selected as representatives of the main families of pollutants present in indoor air. In addition, effects of moisture and desorption of HKUST-1 on adsorption capacity are evaluated.

This study provides new insights into pollutant selectivity mechanisms related to material structure and highlights the potential of HKUST-1 for indoor air treatment.

\section{Experimental and calculation methods}

\subsection{Syntheses of materials}

Copper (II) nitrate trihydrate $\left[\mathrm{Cu}\left(\mathrm{NO}_{3}\right)_{2} \cdot 2 \cdot 5 \mathrm{H}_{2} \mathrm{O}, 98 \%\right]$, benzene-1,3,5 tricarboxylic acid (BTC, 95\%) and ethanol (absolute, EtOH) were obtained from Sigma Aldrich. All materials were used as received without further purification. HKUST-1 was synthesized by scaling up the synthesis protocols described by Bordiga et al. for a $1 \mathrm{~L}$ autoclave where $\mathrm{Cu}\left(\mathrm{NO}_{3}\right)_{2} \cdot 2.5 \mathrm{H}_{2} \mathrm{O}(125 \mathrm{mmol})$ and $\mathrm{BTC}(83.3 \mathrm{mmol})$ were mixed in a solution of $500 \mathrm{~mL}$ of water and ethanol (50:50) in a Teflon-lined stainless steel autoclave [21]. The autoclave was then closed and heated up to $110{ }^{\circ} \mathrm{C}$ for a period of 24 hours. After cooling to room temperature, the product was filtered and thoroughly rinsed with absolute ethanol. The product was finally activated under vacuum at $120^{\circ} \mathrm{C}$ for 24 hours.

\subsection{Materials characterization}

The structure and phase purity of the MOF material were confirmed by powder X-ray diffraction. The characterization was carried out on a Brucker D8 Advance diffractometer (CuK $\alpha_{\alpha 1}$ radiation, $30 \mathrm{kV}, 15 \mathrm{~mA}, \Lambda=$ $1.5406 \AA$ A ) using a step scan mode (0.03 per step) with a range of $5^{\circ}<2 \theta<80^{\circ}$. Pore properties were characterized thanks to a BELSORPmax instrument using a nitrogen adsorption/desorption isotherm at $-196{ }^{\circ} \mathrm{C}$. Specific surface area, pore volume and pore size are respectively determined using the Brunauer-Emmett-Teller (BET) and a MP-Plot methods [22]. Before the adsorption measurements a degassing step was carried out at 180 ${ }^{\circ} \mathrm{C}$ overnight under vacuum in order to remove water, ethanol and other volatile molecules. The thermal behavior of the material was characterized by thermo-gravimetry TGA) and differential scanning calorimetry analysis (DSC) using a SDT Q600 TA instrument. The temperature range was $0-600{ }^{\circ} \mathrm{C}$ with a heating rate of 5 
${ }^{\circ} \mathrm{C} / \mathrm{min}$ in an air atmosphere with a flow rate of $100 \mathrm{~mL} \cdot \mathrm{min}^{-1}$.Scanning electron microscopy (SEM) analysis was carried out using a Philips XL 30 equipment with a high voltage mode of $25 \mathrm{kV}$. Fourier transform infrared (FT-IR) spectrum was recorded at wave numbers ranging from 600 to $1800 \mathrm{~cm}^{-1}$ thanks to a Brucker Vertex 70 with anhydrous $\mathrm{KBr}$ as dispersing agent.

\subsection{Adsorption experiments}

Adsorption of VOCs mixture on HKUST-1 framework was conducted using a homemade flow adsorption equipment (Figure 3) at $23 \pm 1^{\circ} \mathrm{C}$. All the pollutant species were purchased from Air Product S.A.S. as a mixture of air and 5 ppmv of the chemical compounds, their properties are listed in Table 1. The concentrations were adjusted by airflow rates using mass flow controllers.

Relative humidity was controlled using a mixture of dry air and humidified air generated by bubbling air in a water tank. Relative humidity and pollutants concentrations were adjusted by airflow rates using mass flow controllers. Relative humidity was controlled using a Vaisala HMT120 humidity and temperature transmitter. Moist air as well as that pollutants are mixed upstream of the circuit and bleed air charged with pollutants passes through a column (Omnifit ID: $3 \mathrm{~mm}$; OD: $4.5 \mathrm{~mm}$; L: $25 \mathrm{~mm}$ ) containing the adsorbent, maintained in the column with glass wool. The column was stored in a vacuum oven at $180^{\circ} \mathrm{C}$ for 12 hours to activate the material prior each experiment. The activated sample is isolated from pollutants and moisture by a bypass. Next, the contact between the sample and the stabilized mixture of pollutants (including water) is instantiated. In all experiments the columns are filled with a new adsorbent. Chemical analyses of the gas after the adsorption column were carried out by using a Thermal Desorption - Gas Chromatography - Mass Spectrometry / Flame Ionization Detector system (TD-GC-MS/FID). The standard deviations of $\mathrm{C}_{\text {out }} / \mathrm{C}_{\text {in }}$ have been obtained experimentally and are between 0.8 and $3.1 \%$. 


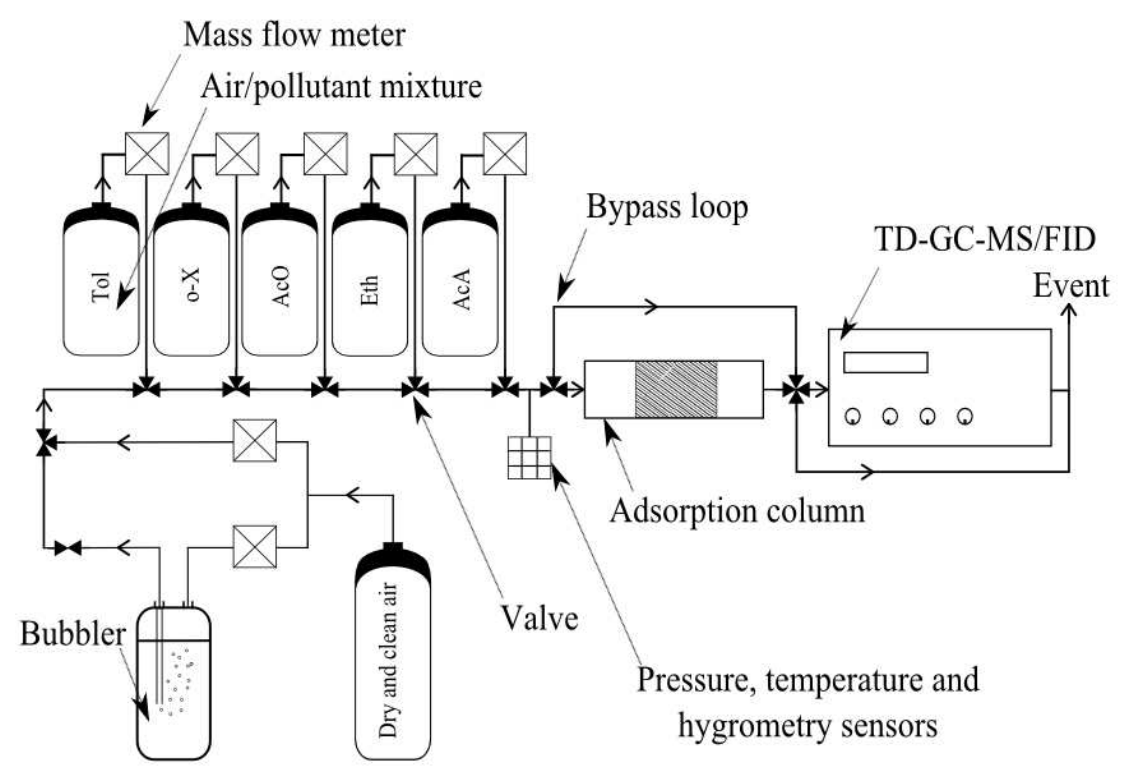

Figure 3: Schematic diagram of the dynamic adsorption equipment.

\begin{tabular}{llllllll}
\hline VOCs & Category & Formula & Short & Molar & Boiling & Kinetic & Dipolar \\
& & & name & mass & point & diameter & moment \\
& & & & $\left(\mathrm{g} \cdot \mathrm{mol}^{-1}\right)$ & $\left({ }^{\circ} \mathrm{C}\right)$ & $(\AA)$ & $(\mathrm{A})$ \\
\hline Toluene & Aromatic & $\mathrm{C}_{7} \mathrm{H}_{8}$ & Tol & 92.14 & 110.8 & 5.7 & 0.37 \\
o-Xylene & Aromatic & $\mathrm{C}_{8} \mathrm{H}_{10}$ & o-X & 106.16 & 144.4 & 7.4 & 0.62 \\
Ethanol & Alcohol & $\mathrm{C}_{2} \mathrm{H}_{6} \mathrm{O}$ & Eth & 46.07 & 78.4 & 4.5 & 1.7 \\
Acetone & Ketone & $\mathrm{C}_{3} \mathrm{H}_{6} \mathrm{O}$ & AcO & 58.08 & 56.5 & 4.8 & 2.9 \\
Acetaldehyde & Aldehyde & $\mathrm{C}_{2} \mathrm{H}_{4} \mathrm{O}$ & AcA & 44.05 & 20.2 & 4.5 & 2.8 \\
\hline
\end{tabular}

Table 1: Properties of selected VOCs[23-26]

Adsorption capacity at saturation $\mathrm{C}_{\mathrm{ads}}(\mathrm{mg} / \mathrm{g})$ stands for the mass of adsorbed $\mathrm{VOC}\left(\mathrm{m}_{\mathrm{Voc}}\right.$ ) per unit weight of adsorbent $\left(m_{a d s}\right) . C_{a d s}$ is calculated from integration of the breakthrough curve and using eq. 1. 
$C_{a d s}=\frac{Q \cdot \int_{t i}^{t f}\left(C_{i n}(t)-C_{o u t}(t)\right) d t}{m_{a d s}}$ eq. 1

Where $Q$ is the total flow rate $\left(\mathrm{m}^{3} \cdot \mathrm{h}^{-1}\right), \mathrm{C}_{\text {in }}$ and $\mathrm{C}_{\text {out }}$ are respectively the concentrations at the inlet and at the

outlet of the adsorption column $\left(\mathrm{mg} \cdot \mathrm{m}^{-3}\right)$, $t_{\mathrm{i}}$ is the time when introduction of the pollutant begins $(\mathrm{h})$ and $\mathrm{t}_{\mathrm{f}}$ is the time to reach $100 \%$ of saturation.

The selectivity $\left(\alpha_{A / B}\right)$ of a mixture of two gases ( $A$ and $B$ ) on a material is calculated using eq. 2:

$\propto_{A / B}=\frac{C_{a d s, A} \cdot C_{B}}{C_{a d s, B} \cdot C_{A}}$ eq. 2

$C_{a d s, A}$ and $C_{a d s, B}$ represent the adsorption capacities of compounds $A$ and $B$ and $C_{A}$ and $C_{B}$ are their associated molar concentrations in the gas phase. If the selectivity is higher than 1 , the compound $A$ is preferentially adsorbed, if the selectivity is lower than 1 , the compound B is preferred.

3. Results and discussion

3.1 Characterization results 

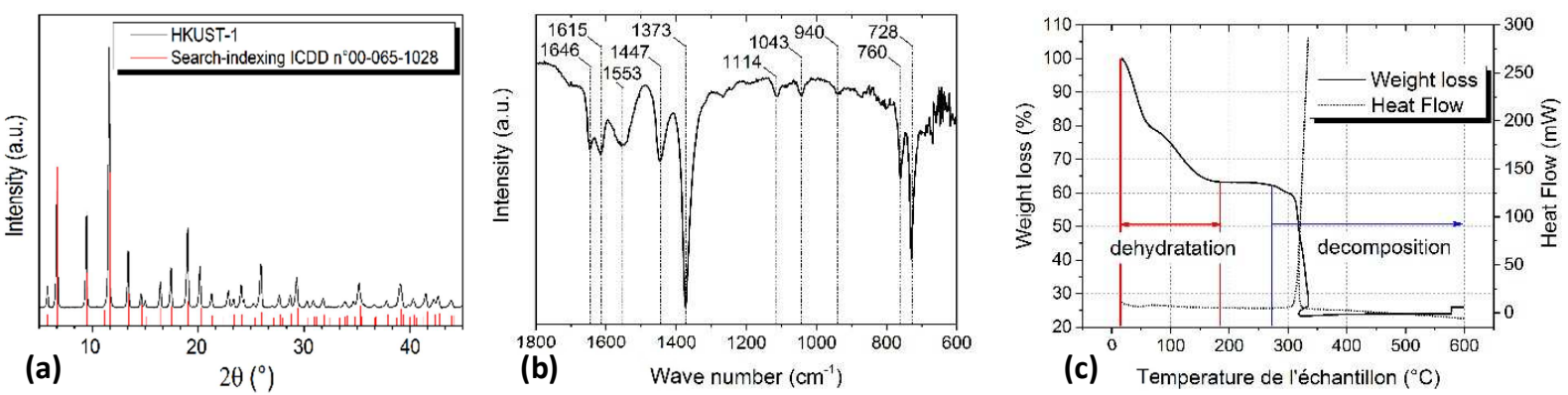

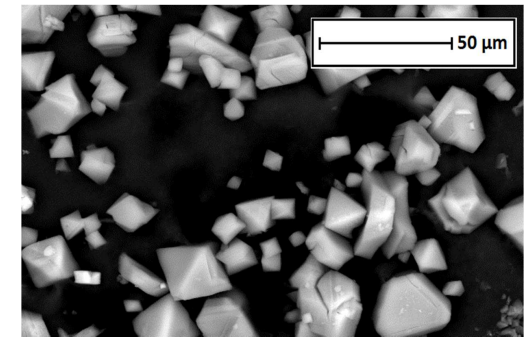

(d)

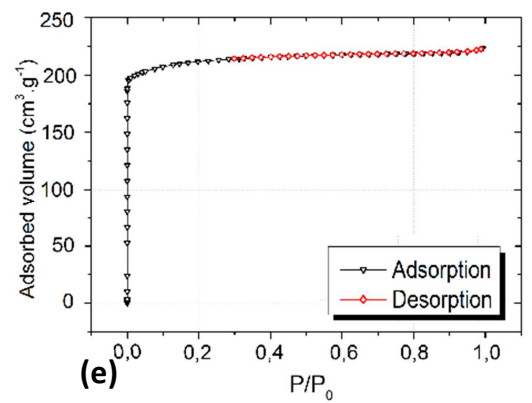

Figure 4: XRD pattern (a), FT-IR spectrum (b), TGA/DSC curve (c), SEM image (d), nitrogen adsorption isotherm (e) of HKUST-1.

The X-ray diffraction pattern of the synthesized HKUST-1 sample (Figure $\mathbf{4}(\mathbf{a})$ ) is in good agreement with the data reported by Wong-Ng et al. and confirms the successful synthesis of the MOF [27]. HKUST-1 was also characterized by FT-IR (the spectrum is shown on Figure 4 (b). The 1646, 1447, and $1373 \mathrm{~cm}^{-1}$ peaks are the stretching vibrations of $\mathrm{COO}-\mathrm{Cu}_{2}$. The peaks located at 728,760 and $940 \mathrm{~cm}^{-1}$ are the stretching vibration of C$\mathrm{CO}_{2}$ and the $1114 \mathrm{~cm}^{-1}$ peak is the stretching vibration of $\mathrm{C}-\mathrm{O}$. The 1615 and $1553 \mathrm{~cm}^{-1}$ peaks can be assigned to $\mathrm{C}=\mathrm{C}$ stretching vibration of the aromatic rings of BTC molecules. These stretching vibrations are in good agreement with data already reported in literature $[28,29]$. The TGA curve illustrated in Figure 4 (c) shows three weight loss stages. The first mass loss $(21.2 \%)$ is attributed to the dehydration of the material $\left(20-120^{\circ} \mathrm{C}\right)$. The second weight loss $(15.7 \%)$ is desorption of water molecules that are bonded on copper atoms $\left(120-180{ }^{\circ} \mathrm{C}\right)$. The third weight loss (39.4\%) is attributed the decomposition of HKUST-1 framework $\left(280-340{ }^{\circ} \mathrm{C}\right)$ is in line with the theoretical loss of $36.7 \%$ [30]. Furthermore, the DSC analysis shows an exothermic peak corresponding to the formation of crystalline Cu oxide phases [30,31]. The SEM image shown in Figure 4 (d) reveals particles with the expected octahedral morphology [30] with crystal sizes between 5 and $20 \mu \mathrm{m}$. Figure 4 (e) shows the $\mathrm{N}_{2}$ 
adsorption/desorption isotherm of the HKUST-1. A type I isotherm characteristic of a microporous material is observed. The specific surface area and total pore volume calculated by the Brunauer, Emmett and Teller method are about $1122.4 \mathrm{~m}^{2} / \mathrm{g}$ and $0.47 \mathrm{~cm}^{3} / \mathrm{g}$ respectively. The pore size calculated by the MP-plot method is $7.4 \AA$ A comparable to the values from Al-Janabi et al. [32].

\subsection{Adsorption capacity of selected VOCs: single component breakthrough experiments}

Toluene, o-xylene, ethanol, acetone and acetaldehyde are used as model molecules in order to simulate the main families of pollutants present in indoor air. Their adsorption capacities obtained from the breakthrough curves under ambient conditions $\left(\mathrm{T}=23{ }^{\circ} \mathrm{C}\right.$, concentration $=2.5 \pm 0.01 \mathrm{ppmv}$, total flow rate $=750 \mathrm{~mL} \cdot \mathrm{min}^{-1}$, sample mass $\approx 10 \mathrm{mg}$ ) are compared to reported literature value in Table 2 . Thanks to the well-known ability of the unsaturated copper cations to catch polar molecules through electrostatic and $\pi-\pi$ interactions, HKUST-1 exhibits high adsorption capacities [14,33]. Indeed, for toluene, o-xylene, ethanol, acetone and acetaldehyde, adsorption capacities are respectively $23.8,14.7,16.5,5.0$ and $1.4 \%$ wt. Adsorption capacities of our synthetized HKUST-1 for toluene and o-xylene are comparable with the values of earlier studies [18-20]. Molecular structure, polarity and boiling point of VOCs are crucial factors for adsorption onto adsorbents [34]. A molecule with a higher boiling point will be more easily absorbed due to stronger intermolecular forces [34]. In our case, adsorption capacities were observed to follow this trend, except for o-xylene, suggesting that other physical parameters are to be taken into account. 


\begin{tabular}{|c|c|c|c|c|}
\hline \multirow[t]{2}{*}{ Adsorbates } & \multicolumn{2}{|l|}{ Conditions } & \multirow{2}{*}{$\begin{array}{l}\mathrm{C}_{\mathrm{ads}} \\
\text { \%wt }\end{array}$} & \multirow[t]{2}{*}{ Refs. } \\
\hline & $C_{\text {in }}$ (ppmv) & $\mathrm{T}\left({ }^{\circ} \mathrm{C}\right)$ & & \\
\hline & & & & Present \\
\hline \multirow[t]{5}{*}{ Tol } & 2.5 & 23 & 23.8 & work \\
\hline & 99 & 25 & 15.9 & [20] \\
\hline & 950000 & 25 & 57.1 & [18] \\
\hline & 920000 & 25 & 58.1 & [19] \\
\hline & & & & Present \\
\hline \multirow[t]{3}{*}{$0-X$} & 2.5 & 23 & 14.7 & work \\
\hline & 6000 & 125 & 29.2 & [35] \\
\hline & & & & Present \\
\hline \multirow[t]{2}{*}{ Eth } & 2.5 & 23 & 16.5 & work \\
\hline & & & & Present \\
\hline \multirow[t]{2}{*}{$\mathrm{AcO}$} & 2.5 & 23 & 5.0 & work \\
\hline & & & & Present \\
\hline AcA & 2.5 & 23 & 1.4 & work \\
\hline
\end{tabular}

Table 2: Adsorption capacity of HKUST-1 for selected VOCs.

Although HKUST-1 show high single-component adsorption capacities, its efficiency for indoor air purification will depend on its behavior in realistic conditions, i.e. in the presence of a mixture of pollutants. IAST model [33] could be used to anticipate mixture behavior from single-component adsorption experiments, but it was shown that when using an adsorbent with a large structural and chemical heterogeneity like HKUST-1, predicitions 
could failed. For example, regarding HKUST-1, Van Assche et al. have shown that free metal sites located in biggest pores would preferentially adsorb polar molecules [33].

\subsection{Competition between pollutants: dual-components breakthrough experiments}

Finally, the adsorption of a single pollutant only makes it possible to estimate the maximum adsorption capacity of this adsorbate in a mixture and it is really difficult to predict the molecule/adsorbent affinities when a mixture of VOC is used. Experimental tests are therefore still required to assess the performance of an adsorbent in realistic conditions.

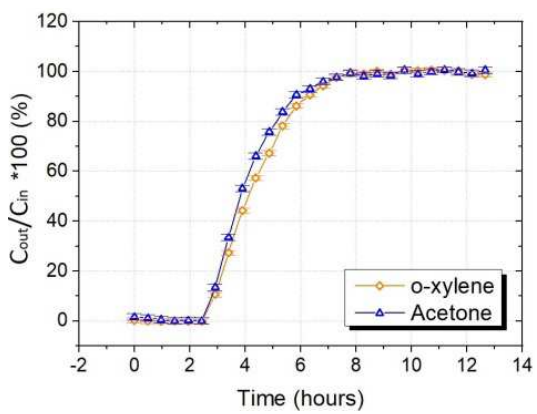

(a)

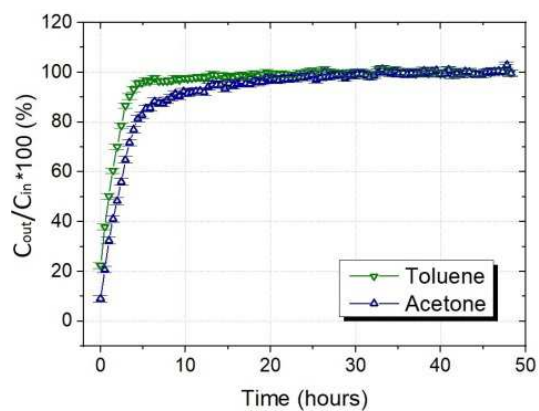

(b)

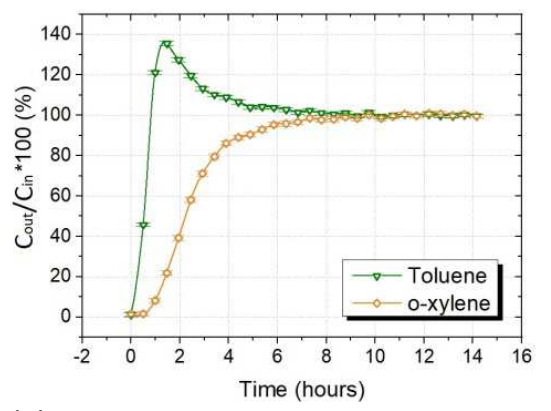

(c)

Figure 5: Breakthrough curves of o- $\mathrm{X} / \mathrm{AcO}(\mathrm{a}), \mathrm{Tol} / \mathrm{AcO}(\mathrm{b})$ and Tol/o-X (c). Total concentration $=2.5 \pm 0.01 \mathrm{ppmv}$, total flow rate $=750 \mathrm{~mL} / \mathrm{min}$.

\begin{tabular}{|c|c|c|c|c|c|c|}
\hline \multirow[t]{3}{*}{ Adsorbates } & \multicolumn{6}{|c|}{$\mathbf{C}_{\text {ads }}$} \\
\hline & \multicolumn{2}{|c|}{ o-X/AcO } & \multicolumn{2}{|c|}{ Tol/AcO } & \multicolumn{2}{|c|}{ Tol/o-X } \\
\hline & Wt\% & mmol.g ${ }^{-1}$ & Wt\% & mmol.g $^{-1}$ & Wt\% & mmol.g ${ }^{-1}$ \\
\hline o-X & 5.6 & 0.53 & - & - & 10.1 & 0.95 \\
\hline $\mathrm{AcO}$ & 2.8 & 0.48 & 4.6 & 0.79 & - & - \\
\hline Tol & - & - & 3.3 & 0.36 & 0.0 & 0.0 \\
\hline Selectivity & 2.0 & 1.1 & 0.7 & 0.45 & 9. $10^{-4}$ & $1.10^{-6}$ \\
\hline
\end{tabular}

Table 3: Adsorption capacity and selectivity for VOCs mixtures. 
In order to understand the competition phenomena of a pollutant mixture during adsorption, adsorption capacities were measured using binary mixtures. The adsorption breakthrough curves for o- $\mathrm{X} / \mathrm{AcO}, \mathrm{Tol} / \mathrm{AcO}$ and Tol/o-X mixtures (concentration $=1.25 \mathrm{ppmv}$ for each pollutant) are presented in Figure 5(a), (b) and (c) and the corresponding selectivities are listed in Table 3.

When using a o-X/Tol mixture, a strong roll-up effect was observed, resulting in the selective adsorption of o- $\mathrm{X}$ only. However, no roll-up effect was observed on the breakthrough curves for the adsorption of o-X/AcO and Tol/AcO mixtures, which suggests that the selectivity is kinetic-driven i.e. based on the difference of molecules diffusion rate in the pores, this type of selectivity being typically observed for molecules with different kinetic diameters but close to the pore diameter of the material [36]. A larger molecule will therefore tend to diffuse less in depth than the less voluminous molecule resulting in a shorter breakthrough time compared to the second molecule. Terencio et al. have shown that acetone fit in the smallest $6 \AA$ pores (with a triangular shaped window of $4.5 \AA$ ) [37], while the larger o-X and Tol, with kinetic diameters of respectively 5.7 and $7.4 \AA$ are not expected to enter these pores. Therefore, in the case of the Tol/o- $X$ mixture, both pollutants are expected to be competitively adsorbed only in large pores and then the adsorbed toluene is moved by o-xylene. This roll-up mechanism suggests that the final selectivity responds only to thermodynamic considerations, o-xylene being preferentially adsorbed relative to toluene because of its higher boiling point and polarity. In the case of o$\mathrm{X} / \mathrm{AcO}$ and Tol/AcO mixtures, the acetone might be adsorbed in the side pockets, while also being adsorbed on the free metal sites located in biggest pores, which would preferentially adsorb polar molecules [33]. Indeed, in the three studied cases, a total amount of $\approx 1 \mathrm{mmol} \cdot \mathrm{g}^{-1}$ of adsorbed species was measured. While a total amount of $\approx 1 \mathrm{mmol} . \mathrm{g}^{-1}$ of $\mathrm{o}-\mathrm{X}$ was adsorbed for the binary $\mathrm{o}-\mathrm{X} / \mathrm{Tol}$, only $\approx 0.5 \mathrm{mmol} . \mathrm{g}^{-1}$ was adsorbed when in competition with acetone, indicating a competition in the large pore. To explain this phenomenon, as no roll-up effect was observed, the selectivity may be due to stronger chemical interactions between $\mathrm{Cu}^{2+}$ centers and 
acetone ( $\mathrm{C} u$ ' $\mathrm{O}$ interaction) than o- $\mathrm{X}$, this effect being even more intense when in competition with toluene $(\approx 0.8$ mmol.g $\mathrm{g}^{-1}$ of adsorbed acetone). Finally, the binary component breakthrough experiments show that molecules are adsorbed in the following order: $\mathrm{O}-\mathrm{X}>\mathrm{AcO}>\mathrm{Tol}$.

\subsection{Multi-component breakthrough experiments and influence of relative humidity}

In agreement with adsorption results of binary mixtures, multi-pollutant breakthrough curves (Total concentration $=2.5 \pm 0.01 \mathrm{ppmv}$, total flow rate $=750 \mathrm{~mL} \cdot \mathrm{min}^{-1}$ ) show that o-X and AcO with respective adsorption capacities of 13.5 and $4.7 \%$ were preferentially adsorbed when using the five-gas mixture (Figure 6a). Furthermore, no toluene was adsorbed, whereas $1.4 \%$ of ethanol and $0.4 \%$ of acetaldehyde were adsorbed probably thanks to the steric selectivity of the side pockets and the $\mathrm{Cu}$ '” $\mathrm{O}$ interactions. Binary mixture experiments showed that toluene was moved by o-xylene, which is also the case for the five gas mixture, while acetone could be adsorbed in the side-pockets and in the biggest pores. Finally, the order of adsorption is o- $\mathrm{X}$ $>$ AcO $>$ Eth $>$ AcA $>$ Tol.

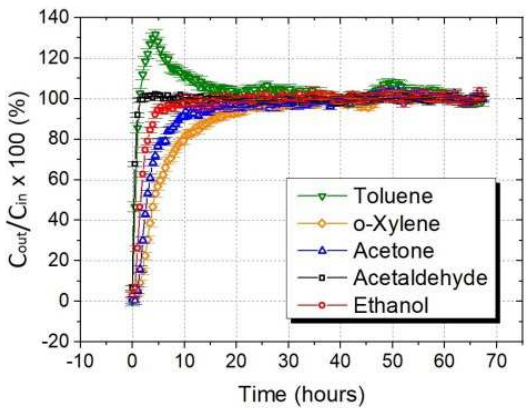

(a)

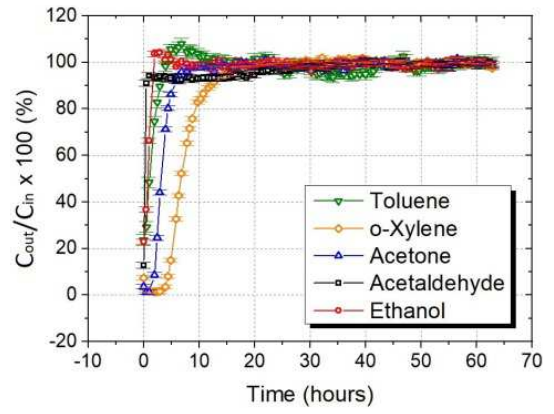

(b)

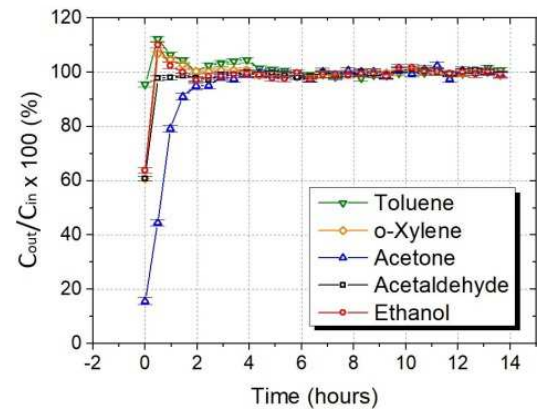

(c)

Figure 6: Breakthrough curves at $\mathrm{RH}=0 \%$ (a), $\mathrm{RH}=20 \%$ (b) and $\mathrm{RH}=40 \%$ (c). Total concentration $=2.5$ $\pm 0.01 \mathrm{ppmv}$, total flow rate $=750 \mathrm{~mL} / \mathrm{min}$.

Relative humidity (RH) affects the adsorbent performances, especially since the concentration of water molecules is very high (at room temperature, $20 \% \mathrm{RH}$ equals about $5600 \mathrm{ppmv}$ ). To evaluate the impact of this competition on the adsorption capacity of the material, HKUST-1 framework was tested at room temperature at 0, 20 and $40 \%$ RH (Figure 6). Adsorption capacities summarized in Table 4 show that an increase in relative 
humidity decreases the amount of adsorbed pollutants, the total adsorption capacity decreasing by $43 \%$ and 97 $\%$ at 20 and $40 \mathrm{RH} \%$ respectively. However, a significant amount of acetone and acetaldehyde is still adsorbed on the material at relatively high relative humidity, showing a stronger interactions of these molecules than water with Cu sites. This could be link to their higher dipolar moments (respectively 2.8 and 2.9 compared to 1.8 for water) leading to the interactions between $\mathrm{Cu}(\mathrm{II})$ site and carbonyl functions [37]. Because of their higher binding energies, these molecules can displace pre-adsorbed water molecules on unsaturated metal centers [38]. In addition, when the HKUST-1 frame is hydrated, the entrance of the side pockets is reduced from 4.5 to 3.5 $\AA$ and may become too narrow for small molecules such as acetone, acetaldehyde and ethanol, further reducing the total adsorption capacity of the material. It is also interesting to note that the toluene affinity change as a function of the $\mathrm{RH}$ value. For $\mathrm{RH}=0 \%$, the adsorption order is o- $\mathrm{X}>\mathrm{AcO}>\mathrm{Eth}>\mathrm{AcA}>\mathrm{Tol}$ while at $\mathrm{RH}=$ $20 \%$, the order is $\mathrm{O}-\mathrm{X}>\mathrm{AcO}>\mathrm{Tol}>\mathrm{Eth}>\mathrm{AcA}$. The toluene molecules are the least polar of the mixture, in view of the results, we can assume their adsorption is less affected by the saturation of the dimer copper by water molecules.

\begin{tabular}{llll}
\hline Adsorbates & \multicolumn{2}{l}{$\mathbf{C}_{\text {ads }}(\mathbf{W t} \%)$} & \\
& $\mathbf{R H}=\mathbf{0 \%}$ & $\mathbf{R H}=\mathbf{2 0 \%}$ & $\mathbf{R H}=\mathbf{4 0 \%}$ \\
\hline Tol & 0.0 & 1.5 & 0 \\
o-X & 13.5 & 7.4 & 0.0 \\
Eth & 1.4 & 0.4 & 0.0 \\
AcO & 4.7 & 2.1 & 0.3 \\
AcA & 0.4 & 0.1 & 0.1 \\
Total & $\mathbf{1 9 . 9}$ & $\mathbf{1 1 . 5}$ & $\mathbf{0 . 4}$ \\
\hline
\end{tabular}

Table 4: Influence of relative humidity on the adsorption capacities.

\subsection{Effect adsorption/desorption cycles on adsorption capacity}


Three consecutive adsorption-desorption cycles were carried out on the same adsorption column with a mixture of pollutants (concentration $=1 \mathrm{ppmv}$ for each pollutant). Desorptions were performed by switching the gas mixture to a clean air flow rate at $750 \mathrm{~mL} \cdot \mathrm{min}^{-1}$. The breakthrough curves (Figure 7(a)) show that molecules are adsorbed and desorbed respectively in the following orders: $\mathrm{O}-\mathrm{X}>\mathrm{AcO}>\mathrm{Eth}>\mathrm{Tol}>\mathrm{AcA}$ and Tol $>\mathrm{AcA}>\mathrm{Eth}>\mathrm{AcO}>0$ $X$. In the early stages of the desorption phase, acetone presents a slower desorption kinetics than xylene but the order is rapidly reversed. After the first cycle, a sharp decrease (43\%) of the adsorption capacity is observed (Figure $\mathbf{7}(\mathbf{b})$, showing the existence of an irreversible fraction of adsorbed pollutants in the material, in agreement with the results of Vellingiri et al., [16]. Then, the adsorption capacity seems to stabilize (just a small decrease between the cycles 2 and 3). The reversible and irreversible fractions of adsorbed pollutants are respectively about 70 and $30 \%$ wt. The use of a desorber gas or the heating of the column can be considered to increase the regeneration of the material and maintain optimum adsorption capacity.

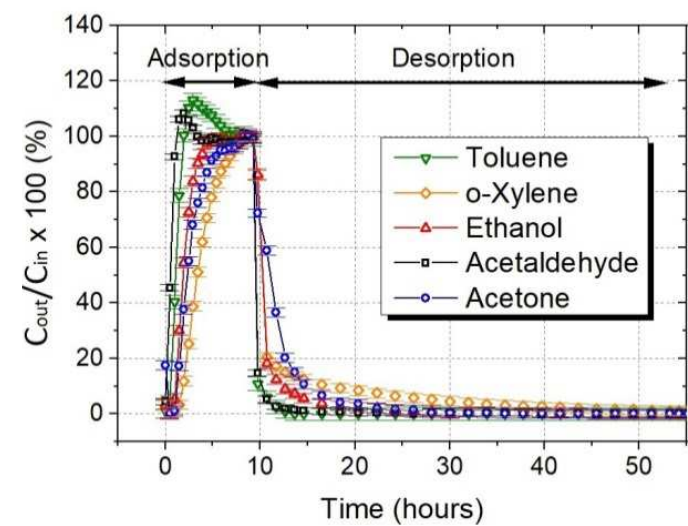

(a)

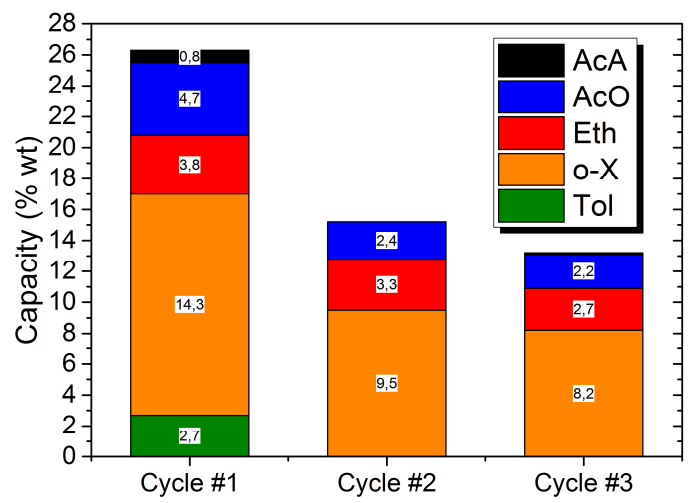

(b)

Figure 7: Adsorption and desorption curves of cycle \# 1 (a) and adsorption capacity of three consecutive adsorption-desorption cycles (b). Total concentration $=2.5 \pm 0.01 \mathrm{ppmv}$, total flow rate $=750 \mathrm{~mL} / \mathrm{min}$.

\section{Conclusion}

Only a few data are available in the literature regarding low concentration adsorption phenomena and realistic relative humidity effects, in particular concerning MOFs. At these concentration ranges, the adsorption capacities for acetone, ethanol and acetaldehyde are not known. Thus, investigations have been here performed 
on the adsorption of toluene, o-xylene, acetone, acetaldehyde and ethanol under several conditions: monopollutant, multi-pollutants, under 0,20 and $40 \% \mathrm{RH}$ and under three consecutive adsorption-desorption cycles.

In mono-pollutant conditions, the adsorption capacity of toluene, o-xylene, ethanol, acetone and acetaldehyde were respectively determined as $23.8,14.7,16.5,5.0$, and $1.4 \% w t$. Binary and five gas mixtures adsorption experiments showed that the selectivity was controlled by steric selectivity in the side pockets and Cu' adsorbate interaction in large pores. This study further highlight the necessity to carry out tests in multipollutants conditions to assess adsorbent performance. Here, it was observed that toluene, a commonly used adsorbate to study material adsorption properties, is adsorbed in large proportion during single-component, but however is very poorly adsorbed when mixed up with other gases.

Adsorption capacities of copper BTC framework drop sharply when increasing relative humidity. Indeed, at 0 $\mathrm{RH} \%$ the total adsorption capacity is around $20 \% \mathrm{wt}$, at $40 \%$ it is closed to $0 \%$. Thus, this material is well adapted for dry air applications such as aircraft cabins depollution.

The total adsorption capacity of the material drops after the first cycle of adsorption/desorption (26.4 \%wt) and then stabilizes around $14 \% \mathrm{wt}$, thus showing the reversible and irreversible fraction of adsorbed pollutants in the material.

\section{Funding}

This work was supported by the CEA-Liten Institute, France and SAFRAN Filtration Systems, France.

\section{References}

[1] G. Gałęzowska, M. Chraniuk, L. Wolska, In vitro assays as a tool for determination of VOCs toxic effect on respiratory system: A critical review, TrAC Trends Anal. Chem. 77 (2016) 14-22.

[2] International Agency for Research on Cancer, Biennial Report (2015) SG/52/2, GC58/2

[3] World Health Organization, ed., Who guidelines for indoor air quality: selected pollutants, WHO, Copenhagen, 2010. 
[4] R. Rajamanickam, D. Baskaran, Biodegradation of gaseous toluene with mixed microbial consortium in a biofilter: steady state and transient operation, Bioprocess Biosyst. Eng. 40 (2017) 1801-1812.

[5] Z. Cheng, L. Lu, C. Kennes, J. Yu, J. Chen, Treatment of gaseous toluene in three biofilters inoculated with fungi/bacteria: Microbial analysis, performance and starvation response, J. Hazard. Mater. 303 (2016) 8393.

[6] Z. Ye, J.-M. Giraudon, N. Nuns, P. Simon, N. De Geyter, R. Morent, J.-F. Lamonier, Influence of the preparation method on the activity of copper-manganese oxides for toluene total oxidation, Appl. Catal. B Environ. 223 (2018) 154-166.

[7] Z. Shayegan, C.-S. Lee, F. Haghighat, TiO 2 photocatalyst for removal of volatile organic compounds in gas phase - A review, Chem. Eng. J. 334 (2018) 2408-2439.

[8] S. Jafari, F. Ghorbani-Shahna, A. Bahrami, H. Kazemian, Adsorptive removal of toluene and carbon tetrachloride from gas phase using Zeolitic Imidazolate Framework-8: Effects of synthesis method, particle size, and pretreatment of the adsorbent, Microporous Mesoporous Mater. 268 (2018) 58-68.

[9] M. Shafiei, M.S. Alivand, A. Rashidi, A. Samimi, D. Mohebbi-Kalhori, Synthesis and adsorption performance of a modified micro-mesoporous MIL-101(Cr) for VOCs removal at ambient conditions, Chem. Eng. J. 341 (2018) 164-174.

[10] L. Yu, L. Wang, W. Xu, L. Chen, M. Fu, J. Wu, D. Ye, Adsorption of VOCs on reduced graphene oxide, J. Environ. Sci. 67 (2018) 171-178.

[11] M. Bahri, F. Haghighat, H. Kazemian, S. Rohani, A comparative study on metal organic frameworks for indoor environment application: Adsorption evaluation, Chem. Eng. J. 313 (2017) 711-723.

[12] D. Peralta, G. Chaplais, A. Simon-Masseron, K. Barthelet, C. Chizallet, A.-A. Quoineaud, G.D. Pirngruber, Comparison of the Behavior of Metal-Organic Frameworks and Zeolites for Hydrocarbon Separations, J. Am. Chem. Soc. 134 (2012) 8115-8126.

[13] D. Britt, D. Tranchemontagne, O.M. Yaghi, Metal-organic frameworks with high capacity and selectivity for harmful gases, Proc. Natl. Acad. Sci. 105 (2008) 11623-11627.

[14] D. Ongari, D. Tiana, S.J. Stoneburner, L. Gagliardi, B. Smit, Origin of the Strong Interaction between Polar Molecules and Copper(II) Paddle-Wheels in Metal Organic Frameworks, J. Phys. Chem. C. 121 (2017) 15135-15144.

[15] K. Vellingiri, J.E. Szulejko, P. Kumar, E.E. Kwon, K.-H. Kim, A. Deep, D.W. Boukhvalov, R.J.C. Brown, Metal organic frameworks as sorption media for volatile and semi-volatile organic compounds at ambient conditions, Sci. Rep. 6 (2016).

[16] K. Vellingiri, P. Kumar, A. Deep, K.-H. Kim, Metal-organic frameworks for the adsorption of gaseous toluene under ambient temperature and pressure, Chem. Eng. J. 307 (2017) 1116-1126.

[17] D. Farrusseng, C. Daniel, C. Gaudillère, U. Ravon, Y. Schuurman, C. Mirodatos, D. Dubbeldam, H. Frost, R.Q. Snurr, Heats of Adsorption for Seven Gases in Three Metal-Organic Frameworks: Systematic Comparison of Experiment and Simulation, Langmuir. 25 (2009) 7383-7388.

[18] Y. Li, J. Miao, X. Sun, J. Xiao, Y. Li, H. Wang, Q. Xia, Z. Li, Mechanochemical synthesis of Cu-BTC@GO with enhanced water stability and toluene adsorption capacity, Chem. Eng. J. 298 (2016) 191-197.

[19] F. Xu, S. Xian, Q. Xia, Y. Li, Z. Li, Effect of textural properties on the adsorption and desorption of toluene on the metal-organic frameworks HKUST-1 and MIL-101, Adsorpt. Sci. Technol. 31 (2013) 325-339.

[20] K. Vellingiri, P. Kumar, A. Deep, K.-H. Kim, Metal-organic frameworks for the adsorption of gaseous toluene under ambient temperature and pressure, Chem. Eng. J. 307 (2017) 1116-1126.

[21] S. Bordiga, L. Regli, F. Bonino, E. Groppo, C. Lamberti, B. Xiao, P.S. Wheatley, R.E. Morris, A. Zecchina, Adsorption properties of HKUST-1 toward hydrogen and other small molecules monitored by IR, Phys. Chem. Chem. Phys. 9 (2007) 2676.

[22] S. Brunauer, L.S. Deming, W.E. Deming, E. Teller, On a theory of the van der Waals adsorption of gases, J. Am. Chem. Soc. 62 (1940) 1723-1732. 
[23] A. Gauf, C. Navarro, G. Balch, L.R. Hargreaves, M.A. Khakoo, C. Winstead, V. McKoy, Low-energy elastic electron scattering by acetaldehyde, Phys. Rev. A. 89 (2014).

[24] Y. Marcus, The properties of solvents, Wiley, New York, 1998.

[25] A.P. Altschuller, The dipole moments of hydrocarbons, J Phys. Chem 57 (1953) 538-540.

[26] M. MALACRIA, J.-P. GODDARD, C. OLLIVIER, G. GOUHIER, Chimie supportée sur phase solide, Tech. Ing. Constantes Phys.-Chim. 5 (2008).

[27] W. Wong-Ng, J.A. Kaduk, D.L. Siderius, A.L. Allen, L. Espinal, B.M. Boyerinas, I. Levin, M.R. Suchomel, J. llavsky, L. Li, Reference diffraction patterns, microstructure, and pore-size distribution for the copper (II) benzene-1, 3, 5-tricarboxylate metal organic framework (Cu-BTC) compounds, Powder Diffr. 30 (2015) 213.

[28] T. Toyao, K. Liang, K. Okada, R. Ricco, M.J. Styles, Y. Tokudome, Y. Horiuchi, A.J. Hill, M. Takahashi, M. Matsuoka, P. Falcaro, Positioning of the HKUST-1 metal-organic framework $\left(\mathrm{Cu}_{3}(\mathrm{BTC})_{2}\right)$ through conversion from insoluble Cu-based precursors, Inorg. Chem. Front. 2 (2015) 434-441.

[29] N.R. Dhumal, M.P. Singh, J.A. Anderson, J. Kiefer, H.J. Kim, Molecular Interactions of a Cu-Based MetalOrganic Framework with a Confined Imidazolium-Based Ionic Liquid: A Combined Density Functional Theory and Experimental Vibrational Spectroscopy Study, J. Phys. Chem. C. 120 (2016) 3295-3304.

[30] N. Al-Janabi, P. Hill, L. Torrente-Murciano, A. Garforth, P. Gorgojo, F. Siperstein, X. Fan, Mapping the CuBTC metal-organic framework (HKUST-1) stability envelope in the presence of water vapour for $\mathrm{CO} 2$ adsorption from flue gases, Chem. Eng. J. 281 (2015) 669-677.

[31] K.-S. Lin, A.K. Adhikari, C.-N. Ku, C.-L. Chiang, H. Kuo, Synthesis and characterization of porous HKUST-1 metal organic frameworks for hydrogen storage, Int. J. Hydrog. Energy. 37 (2012) 13865-13871.

[32] M.A. Lillo-Rodenas, A.J. Fletcher, K.M. Thomas, D. Cazorla-Amoros, A. Linares-Solano, Competitive adsorption of a benzene-toluene mixture on activated carbons at low concentration, Carbon. 44 (2006) 1455-1463.

[33] T.R.C. Van Assche, T. Duerinck, S. Van der Perre, G.V. Baron, J.F.M. Denayer, Prediction of Molecular Separation of Polar-Apolar Mixtures on Heterogeneous Metal-Organic Frameworks: HKUST-1, Langmuir. 30 (2014) 7878-7883.

[34] X. Zhang, B. Gao, A.E. Creamer, C. Cao, Y. Li, Adsorption of VOCs onto engineered carbon materials: A review, J. Hazard. Mater. 338 (2017) 102-123.

[35] D. Peralta, K. Barthelet, J. Pérez-Pellitero, C. Chizallet, G. Chaplais, A. Simon-Masseron, G.D. Pirngruber, Adsorption and Separation of Xylene Isomers: CPO-27-Ni vs HKUST-1 vs NaY, J. Phys. Chem. C. 116 (2012) 21844-21855.

[36] C.R. Reid, K.M. Thomas, Adsorption Kinetics and Size Exclusion Properties of Probe Molecules for the Selective Porosity in a Carbon Molecular Sieve Used for Air Separation, J. Phys. Chem. B. 105 (2001) 10619-10629.

[37] T. Terencio, F. Di Renzo, D. Berthomieu, P. Trens, Adsorption of Acetone Vapor by Cu-BTC: An Experimental and Computational Study, J. Phys. Chem. C. 117 (2013) 26156-26165.

[38] N. Nijem, K. Fürsich, H. Bluhm, S. R. Leone, M. K. Gilles, Ammonia Adsorption and Co-adsorption with Water in HKUST-1: Spectroscopic Evidence for Cooperative Interaction, J. Phys. Chem. C. 119 (2015) 24781-24788. 